\title{
The Effect of Speos Method on the Quality of Postpartum Mother life at Mertoyudan I and Mertoyudan 2 Primary Health Center in 2018
}

RISKY PUJI WULANDARI ${ }^{1}$, MUFDILLAH ${ }^{2}$

${ }^{1}$ Student of Postgraduate Midwifery Programs, Faculty of Health Sciences, Aisyiyah University, West Ringroad 63 MlangiNogotirto Street GampingSleman 55292, Yogyakarta, Indonesia

'Lecturer at the Department of Midwifery, Faculty of Health Sciences, Aisyiyah University, West Ringroad 63 MlangiNogotirto Street GampingSleman 55292, Yogyakarta, Indonesia

Coresponden author to Risky Puji Wulandari email : riskypujiw@gmail.com,mufdillah.stikes@gmail.com

\begin{abstract}
Background: Postpartum mothers are potentially susceptible to postpartum care complications, such as postpartum blues and depression. SPEOS is a combination of endorphin massage techniques, oxytocin massage, and positive suggestions to improve life quality after childbirth.

Aim: This study aimed to prove the SPEOS method's effectiveness on postpartum mothers' quality of life.

Methods: This research was a quasi-experiment with a pretest-posttest control group design. The research was conducted in Mertoyudan I Primary Health Center and Mertoyudan II Health Center. The research subjects were 22 postpartum mothers taken using a simple random sampling technique. The independent variable in this study was the SPEOS method, and the dependent variable was the quality of life. The instrument used was the PQOL questionnaire. The data were analyzed using Wilcoxon and Mann-Whitney tests.

Results: The quality of postpartum mothers life scores increased (mean $=177.55$ to $182.45, \mathrm{Cl}=95 \%, \mathrm{p}=$ 0.000 ), SPEOS method was more effective in improving the quality of life of post partum mothers (mean difference $=4.9, \mathrm{Cl}=95 \%, \mathrm{p}=0,000)$.

Conclusion: The SPEOS method affects improving the quality of life of Postpartum mothers.
\end{abstract}

Keywords: SPEOS, quality of life, postpartum, breastfeeding mothers

\section{INTRODUCTION}

The postpartum period is a critical transition time for approximately six weeks, significantly affecting the mother's physical and mental health after childbirth. The decrease in psychological health can occur in postpartum mothers, so it is necessary to support the mother's adjustment to face the mother to face the activities and her new role as a mother [1]. Psychological problems in postpartum can also interfere with the mother's ability to enjoy her baby's care, affecting life quality through life changes such as lack of sleep, irregular food intake, and dehydration. Psychological factors are things that need to be considered because they can cause maternal psychological changes. This condition can affect the lactation process. The fact shows that the way the hormone oxytocin works is influenced by psychological conditions. The psychological preparation of mothers before breastfeeding is an essential factor that influences the success of breastfeeding. Stress, excessive anxiety, and unhappiness in mothers play a role in exclusive breastfeeding [2]. The SPEOS method (Endorphin, Oxytocin, and Suggestive Massage Stimulation) aims to assist mothers in breast milk production when breast milk production is smooth. It is expected that mothers can enjoy caring for their babies to improve the quality of life after childbirth. Previous research stated that the SPEOS method has been proven to increase breast milk production and provide comfort and confidence to mothers for exclusive breastfeeding for six months but has never been measured against the postpartum quality of life. In this study, the researchers intended to prove the SPEOS method's effect on postpartum mothers' quality of life.

\section{METHODS}

The study was a quasi-experiment with a pretest-posttest control group design. The study was conducted at
Mertoyudan I Primary Health Center and Mertoyudan II Primary Health Center in April-June 2018. This study's population was all postpartum mothers in the working area of Mertoyudan I Primary Health Center and Mertoyudan II Primary Health Center. In this study, 22 postpartum mothers used sampling techniques, namely simple random sampling, who met the inclusion and exclusion criteria. The independent variable in this study was the SPEOS method. This study's dependent variable was the quality of lifebased on postpartum mothers' perception of their quality of life. The instrument used a questionnaire about the quality of life of postpartum mothers by translating the Postpartum Quality of Life questionnaire (PQOL) by Zhou in Indonesian [3]. The confounding variables in this study were education, occupation, and residence status. This was based on four sub-measured variables of the quality of life, and it has been tested the validity and reliability. Univariate analysis was carried out to see the frequency distribution and characteristics of research respondents. The bivariate analysis included a data normality test was carried out to determine the distribution of data. The Wilcoxon test aimed to determine differences in mean scores of life quality before and after treatment using a 95\% confidence level.

Meanwhile, the Mann-Whitney test determined the differences in intervention groups and post-treatment controls using a 95\% confidence level $(\mathrm{Cl})$. Researchers carried out the research ethics by applying for the commission of 'Aisyiyah University Yogyakarta. The Commissioner gave his approval to continue the study with letter number 553/KEP-UNISA/V/2018.

\section{RESULTS}

1. Univariate Analysis: Table 1 shows that most of the mothers in both groups had senior secondary education. This is indicated by maternal presentation of 
$54.5 \%$ in the intervention group and control group. Table 1 shows that most of the mothers in the intervention and control groups were housewives. This was indicated by the presentation of 54.5 in the intervention group and 63.6 in the control group. Table 1 shows that most of the mothers lived separately with parents in both groups. This can be seen from the percentage of 54.5 in the intervention group and 64.6 in the control group. The frequency distribution of the characteristics of research respondents is illustrated in Table 1.

Table 1. Characteristics of Respondents Research

\begin{tabular}{|c|c|c|c|c|}
\hline \multirow{2}{*}{ Variables } & \multicolumn{2}{|c|}{ Intervention } & \multicolumn{2}{|c|}{ Groups Group Control } \\
\hline & $f$ & $(\%)$ & $f$ & (\%) Middle \\
\hline Education & & & & \\
\hline Elementary School & 1 & 9.1 & 1 & 9.1 \\
\hline HighSchool & 6 & 54.5 & 6 & 54.5 \\
\hline Bachelor & 4 & 36.4 & 4 & 36.4 \\
\hline Occupation & & & & \\
\hline Housewife & 6 & 54.5 & 7 & 63.6 \\
\hline Private & 5 & 45.5 & 4 & 36.4 \\
\hline Employees & & & & \\
\hline Living Status & & & & \\
\hline Together & 5 & 45.5 & 4 & 36.4 \\
\hline Separated & 6 & 54.5 & 7 & 64,6 \\
\hline
\end{tabular}

\section{Bivariate Analysis}

a. Data of Normality Test

Normality test data is illustrated in Table 2

Table 2. Data of Normality Test

\begin{tabular}{|l|l|}
\hline Variable & Sign \\
\hline Pre_quality of life & 0,452 \\
Post_quality of life & 0,000 \\
\hline
\end{tabular}

The normality test data results using the Shapiro-WIlk test showed the value of life quality before treatment had standard data $(p=0,452)$. At the same time, quality of life after treatment has abnormal data $(p=0,000)$.

b. The difference in a mean score of quality of life before and after treatment Differences in the mean score of quality of life before and after treatment are illustrated in Table 3.

Table 3. WilcoxonTest

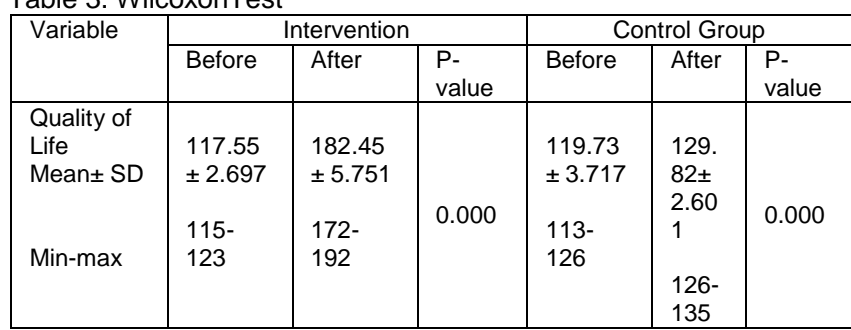

The Wilcoxon test results in table 4 show the mean scores of quality of life in both groups results in both groups had a significant increase $(p=0.000)$.

c. The mean difference in the intervention and control groups after treatment

The mean difference in the intervention and control groups after treatment is illustrated in Table 4.

Table 4. Mann-Whitney Test

\begin{tabular}{|l|l|l|l|}
\hline Variable & Intervention & $\begin{array}{l}\text { Group Control } \\
\text { Group }\end{array}$ & P-value \\
\hline Life Quality & & 6.00 & \\
Mean Rank & 17.00 & 66.00 & 0,000 \\
Sum Of Rank & 187,00 & 6 \\
\hline
\end{tabular}

Mann-Whitney test results in table 4 show that the intervention group had a higher average than the control group. The SPEOS method was more effective in improving the quality of life $(p=0,000)$.

\section{DISCUSSION}

Influence Test aimed to determine differences in quality of life after treatment in both groups using the Mann-Whitney stated that the SPEOS method was more effective in improving the quality of life $(p=0.000)$. It can be seen from the mean difference in the intervention group that was higher than the control group. The SPEOS method combines endorphin massage techniques, oxytocin massage, and suggestive administration (SPEOS). The SPEOS method aims to accelerate breast milk production, provide comfort in breastfeeding, and care for babies. To improve maternal welfare, the SPEOS method can optimally improve the quality of life of other postpartum. Sari's previous research showed an effect of massage stimulation on endorphins, oxytocin, and increased breast milk production in postpartum mothers [4]. Breast milk production for postpartum mothers using the SPEOS method was increased with a p-value of 0.000 and $R R$ 7.750 , whereas the control group with oxytocin obtained $\mathrm{RR}$ 5.050. The SPEOS method is considered more effective for postpartum mothers in facilitating breast milk production. Another study by Anggorowati in her study showed the effect of the SPEOS method on milk production was $131.87(p=00)$, and an increase in infant weight was 483.30gram ( $p$ 0.00) [5]. The SPEOS method affects breast milk production and an increase in infant weight in postpartum mothers in Bengkulu.

The postpartum period is one of the crucial periods and is one of the transitional periods of parenthood in women who need various adjustments [6]. The postpartum period is a critical transition time for approximately six weeks, significantly affecting the mother's physical and mental health after childbirth. The decrease in psychological health can occur in postpartum mothers. Hence, it is necessary to support the mother's adjustment to do the activities and her new role as a mother. 
Postpartum mothers' quality of life is the result of nursing and medical services during the postpartum period. Postpartum nursing care aims to improve the quality of life of postpartum mothers. The inability to give breast milk to the baby has an unfortunate and frustrating effect on caring for the baby. Half of the women said they were very disturbed by her condition. According to Dini, oxytocin massage can contribute to the promotion of maternal health [7]. This study showed an effect of oxytocin message to increase milk production in Plus Mandiangin PrimaryHealth Center Bukittinggi in 2016.

Zubaran has stated that there is a usefulness of breastfeeding and quality of life (QoL) in a sample of 89 mothers from southern Brazil [8]. There is a significant correlation between the scores of the two QoL and BSESSF questionnaires. This study indicates that breastfeeding effectiveness is significantly related to mothers' quality of life in southern Brazil. Other supporting studies by Nabulsi state that exclusive breastfeeding is a cost-effective public health measure that significantly impacts infant morbidity and mortality [9]. In a country with limited healthcare resources like Lebanon, developing an effective breastfeeding promotion and supporting intervention easily replicated across various settings becomes a priority. If positive, this study's results will provide a model to bolster breastfeeding promotion efforts and improve child health in Lebanon and the Middle East and North Africa (MENA) region. This study's results align with Lara, which states that aspects of quality of life will be related to breastfeeding and baby care [10]. Actions to help mothers facilitate milk production in the early postpartum period can improve maternal mental health and life quality. The results of Baghirzada's (2013) study show that physical abilities, child care abilities, pain, and energy influence the quality of life of mothers [11].

\section{CONCLUSION}

The SPEOS method is more effective in improving the quality of life of postpartum mothers.

Suggestions: Health staff at Mertoyudan 1 and Mertoyudan 2 Primary Health Center, especially midwives, should apply the SPEOS method to postpartum women as midwifery scientific development to facilitate breastfeeding and improving the quality of life of postpartum mothers. Besides, midwives are suggested to plan in-service education about the SPEOS method's importance after giving birth. This research aims to explain the SPEOS method needed for breastfeeding mothers to increase their health and quality of life of postpartum mothers. This study can be used as input, reading material, and information for further researchers. Besides, the data should use the assessment about the quality of life in each postpartum home visit that is conducted three times, such as the first
assessment/K1 (3rd to the seventh day of postpartum), the second assessment/K2 (8th-28th day of postpartum), and the third assessment/K3 (29th - 42nd of postpartum), so that information about respondents becomes more complete and general.

\section{REFERENCES}

1. C. Dennis, "Can we identify mothers at risk for postpartum depression in the immediate postpartum period using the Edinburgh Postnatal Depression Scale?," J. Affect. Disord., vol. 78, no. 2, pp. 163-169, Feb. 2004, doi: 10.1016/S01650327(02)00299-9.

2. E. S. Mezzacappa and E. S. Katkin, "Breast-feeding is associated with reduced perceived stress and negative mood in mothers.," Heal. Psychol., vol. 21, no. 2, pp. 187193, 2002, doi: 10.1037/0278-6133.21.2.187.

3. S.-Z. Zhou, X.-L. Wang, and Y. Wang, "Design of a questionnaire for evaluating the quality of life of postpartum women (PQOL) in China," Qual. Life Res., vol. 18, no. 4, pp. 497-508, May 2009, doi: 10.1007/s11136-009-9466-2.

4. N. Sari, A. Soejoenoes, S. Wahyuni, O. Setiani, and C. Anwar, "The Effectiveness of Combination of Oxytocin and Endorphin Massage on Uterine Involution in Primiparous Mothers," Belitung Nurs. J., vol. 3, no. 5, pp. 569-576, Oct. 2017, doi: 10.33546/bnj.193.

5. A. Anggorowati, H. Sutadi, S. Setyowati, and R. A. Koestoer, "Effects of Acupoint Stimulation with Digital Massager of Oxytocin on the Breast Milk Production of Working Mothers," Nurse Media J. Nurs., vol. 6, no. 2, p. 91, Jan. 2017, doi: 10.14710/nmjn.v6i2.11726.

6. B. Torkan, S. Parsay, M. Lamyian, A. Kazemnejad, and A. Montazeri, "Postnatal quality of life in women after normal vaginal delivery and caesarean section," BMC Pregnancy Childbirth, vol. 9, no. 1, p. 4, Dec. 2009, doi: 10.1186/14712393-9-4.

7. P. R. Dini, "The Effect of Hypnobreastfeeding and Oxytocin Massage on Breastmilk Production in Postpartum," J. Med. Sci. Clin. Res., vol. 5, no. 10, Oct. 2017, doi: 10.18535/jmscr/v5i10.19.

8. C. Zubaran, K. Foresti, M. V. Schumacher, M. R. Thorell, L. C. Muller, and A. L. Amoretti, "An assessment of maternal quality of life in the postpartum period in southern Brazil: a comparson of two questionnaires," Clinics, vol. 64, no. 8, pp. 751-756, 2009, doi: 10.1590/S1807-59322009000800007.

9. M. Nabulsi et al., "A complex breastfeeding promotion and support intervention in a developing country: study protocol for a randomized clinical trial," BMC Public Health, vol. 14, no. 1, p. 36, Dec. 2014, doi: 10.1186/1471-2458-14-36.

10. S. Lara-Cinisomo, K. Zhu, K. Fei, Y. Bu, A. P. Weston, and U. Ravat, "Traumatic events: exploring associations with maternal depression, infant bonding, and oxytocin in Latina mothers," BMC Womens. Health, vol. 18, no. 1, p. 31, Dec. 2018, doi: 10.1186/s12905-018-0520-5.

11. L. Baghirzada, K. N. Downey, and A. J. Macarthur, "Assessment of quality of life indicators in the postpartum period," Int. J. Obstet. Anesth., vol. 22, no. 3, pp. 209-216, Jul. 2013, doi: 10.1016/j.ijoa.2013.03.010 